\title{
FUNCTIONAL ANALYSIS IN EMBODIMENT DESIGN - AN INVESTIGATION OF EMBODIMENT FUNCTION RELATIONS IN TESTING ACTIVITIES
}

\author{
Grauberger, Patric; Voß, Katharina; Matthiesen, Sven \\ Karlsruhe Institute of Technology (KIT), IPEK - Institute of Product Engineering
}

\begin{abstract}
Testing contributes to success of engineering design as it plays an important role in gaining insights about the system in development. Literature indicates that for success in engineering design, gaining insights about relations of embodiment and function is crucial. In this contribution, an investigation of how insights about embodiment function relations are gained in testing, is conducted. For this, the testing documentation in a student development project is analysed. The results show a correlation of gaining insights about embodiment function relations to success in engineering design. Potential for improvement in data acquisition and processing is uncovered, which will be used in a succeeding study to investigate this issue in more detail.
\end{abstract}

Keywords: Embodiment design, Design engineering, Functional modelling, Evaluation, Design methods

\section{Contact:}

Grauberger, Patric

Karlsruhe Institute of Technology

IPEK - Institute of Product Engineering

Germany

patric.grauberger@kit.edu

Cite this article: Grauberger, P., Voß, K., Matthiesen, S. (2019) 'Functional Analysis in Embodiment Design - An 


\section{INTRODUCTION}

In engineering design it is necessary for design engineers to pre-think an embodiment of the system in development that enables it to fulfil its functions. They investigate embodiment function relations (EFR) in order to gain a sufficient understanding of the system. As no direct connection of the concrete embodiment and abstract function is possible, this investigation needs to be done via the systems behaviour (Gero and Kannengiesser, 2014). Gain of knowledge about EFRs enables design engineers to define a suitable system embodiment (Matthiesen, 2011).

For representing a system embodiment, behaviour and/or function, product models like sketches, function trees, CAD-models and many more are used. These models contain different aspects of the product. For example a technical drawing documents design parameters and their tolerances, a function tree shows functional structures of the product. However, the documentation and usage of EFRs remains challenging, as bridging the mentioned gap between concrete embodiment and abstract function is often not possible in product models. A tolerance in the technical drawing is precisely documented, however, why it was chosen and how it is related to system behaviour and function cannot be answered from this product model.

Product models that include explicit information about EFRs are mostly analytical, like finite element models or multibody simulation models and therefore need a parameterized product model as basis. The latter is often not present in the early phase of engineering design, where according to the rule of 10, the embodiment can be changed at low expenditure (Ehrlenspiel and Meerkamm, 2017). It can also be difficult to investigate the insights and assumptions on which these models are based on, as the identification of function relevant parameters is often not documented.

With the Characteristics Properties Modelling (Weber, 2014), organ domain models (Andreasen et al., 2015) or the Contact and Channel Approach (Matthiesen, 2002, Albers and Wintergerst, 2014), EFRs can be documented without the need of a parameterized product model as basis. Even if these models are not very common in design practice in industry, similar approaches are used to model relations of cause and effect (Erbe, 2018). The need for explication of EFRs in engineering design seems to be present. As the design process in general shows an iterative character, where problem and solution evolve together in learning cycles of the design engineers (Dorst and Cross, 2001, Wynn et al., 2007, Meboldt et al., 2012), the gain of knowledge about EFRs is iterative as well. Model building and extension of product models in engineering design is often done in iterative testing of assumptions that need to be verified by the design engineers to become knowledge.

Knowledge about EFRs can be gained by testing physical prototypes or through usage of virtual models. Besides verification and validation activities, testing plays an important role for reaching the aim of fulfilled requirements in engineering design (Shabi and Reich, 2012). Testing can be done on different levels of fidelity and system integration, according to the needed insights (Türk et al., 2014; Tahera et al., 2018). It can be differentiated into the four activities of trial and error, experiment, verification and validation (Boes et al., 2017). Causal knowledge about EFRs can only be gained in experimental testing. However, conducting successful experiments is difficult, as for example in measurement, resources can be spent without answering the underlying question of the experiment (Otto and Wood, 2001). A study shows that conducting testing activities influences the success of a design project (Batliner et al., 2019).

The challenge however is, that it remains unclear how exactly testing activities contribute to success in engineering design. Based on the study of Batliner et al. (2019) and the described need to gain knowledge about EFRs, it is assumed that success in embodiment design might be caused by conducting experimental testing activities to gain knowledge about EFRs. This leads to the following research question:

\section{Does the gain of insights about embodiment function relations in experimental testing activities correlate with success in engineering design?}

To answer this question, a field study is conducted, where testing documentation in a student development project is analysed. This study investigates the effect of gain of knowledge about EFRs on success in engineering design. EFRs are identified via processing of the documentation data and are related to a success criterion in engineering design. This study is conducted as field study to investigate how gain of knowledge about EFRs is done in a student course. 


\section{THE INVESTIGATION - STUDY ENVIRONMENT AND METHODS USED}

The following section describes the environment in which the data for the study are collected. The processing of the gained data to measure EFRs and investigate a correlation to the chosen success factor in engineering design is shown.

\subsection{Student course Mechatronic Systems and Processes as study environment}

The study takes place within the course Mechatronic Systems and Processes (MSuP) at the Karlsruhe Institute of Technology. The participants are 84 mechatronics students in their fifth semester of the bachelor's programme as it is a mandatory course for them, and one mechanical engineering student in the master's programme, for whom it is an optional course. They have experience in calculation of electrical circuits, programming and engineering design.

The task for the participating students is to develop a system consisting of two robots in team work during the four-month lecture. Each of these two robots has different tasks and they have to cooperate in a competition against other teams' robot pairs. The task of the considered lecture period (winter semester 2017/18) is to collect different coloured and shaped building blocks using a mobile robot system and then sort them by colour and shape using a stationary robot system to stack cube towers. In the competition, the highest tower according to a point scheme and the most collected building blocks win.

The successful participation in the competition is the only requirement given from the lecturers, the students are free to develop their own strategy on how to fulfil this requirement.

In the lecture and tutorial of this student course, they learn about methods for engineering design, iterative development strategies and testing with prototypes, as iterative prototyping correlates with increasing system performance (Camburn et al., 2017). In a tutorial about testing documentation, they are encouraged to describe all of their testing activities, even if their investigations are possible by modifying only one prototype of the system.

During the development of the robot systems, the students need to examine whether subsystems interact in the intended way and fulfil their functions reliable enough for competition or if they have to be redesigned. Testing is done continuously to improve performance of their product in competition. The objectives and requirements are defined by the students themselves, therefore no formal requirement test is done during the course. For documentation and coordination of testing activities, each team assigns the role of test engineer to one of their members. Testing however is not restricted to the test engineer and can be distributed in the team according to workload.

In the system development, it usually takes iterations to build sufficiently functional prototypes, as their EFRs are very difficult to predict in all aspects and design is often based on vague assumptions. From an initial concept, an embodiment is designed, built and tested to investigate its behaviour and be able to improve it. A difference is, that in corporate environment often simulation models are used for virtual testing. They are allowed in the student course too, however due to the difficulty in building analytical models to investigate EFRs (like FEM-simulation) and the supply in materials for physical testing, they are not used in this semester course.

As engineering design is iterative, it is feasible to measure so called "test series", for which a subsystem is developed until it meets its requirements. Reaching a stage, where all requirements for the subsystem are sufficiently met, can be seen as an indicator for success in engineering design. This definition of success refers to the success criterion "meeting user requirements" introduced in Müller and Turner (2007). The users are stakeholders in the project and can also be internal customers as the team members expect a functioning subsystem (Albers et al., 2016). An example for a test series is shown in Figure 1. 


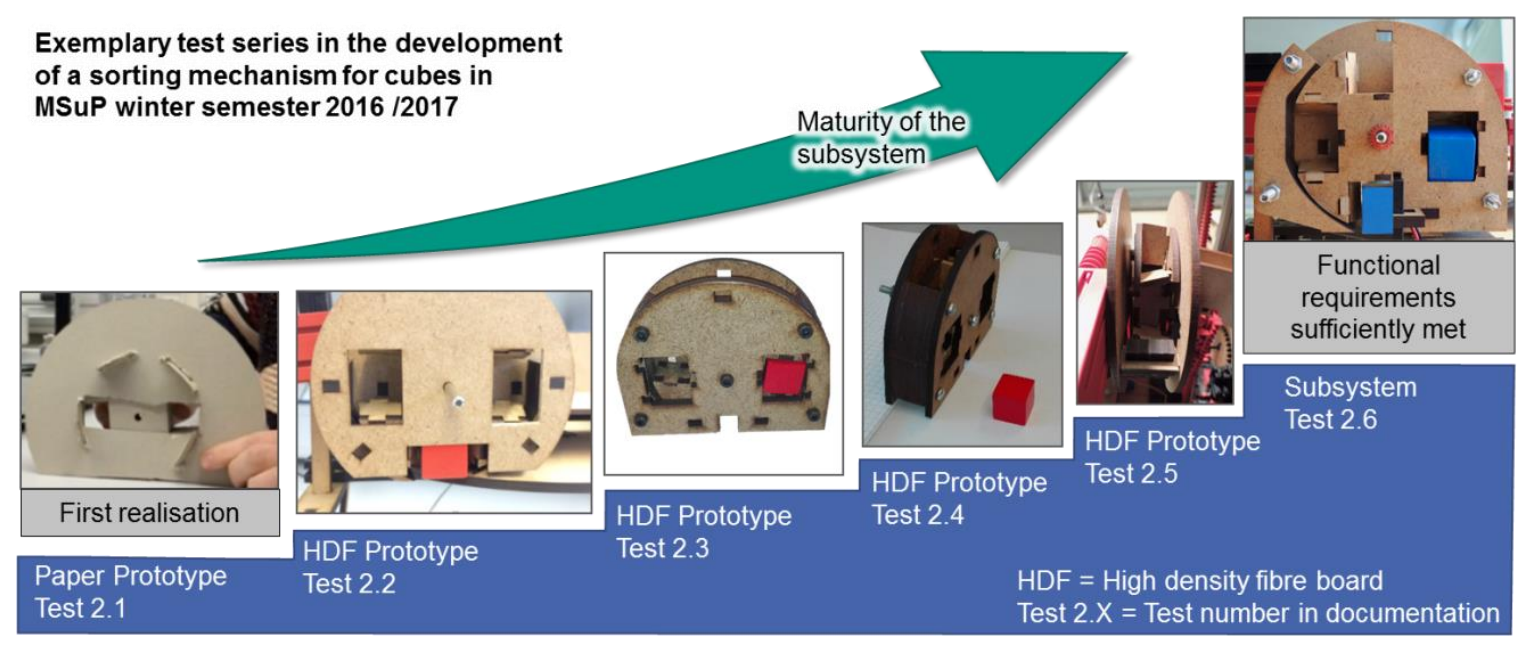

Figure 1: Test series using the example of a sorting mechanism in Mechatronic Systems and Processes (MSuP) according to Matthiesen et al. (2017a)

On the left, the first realisation of the developed concept is depicted. It is made from cardboard, as a first prototype it often is not made from the intended material of the final subsystem. Its aim is to clarify the concept and verify its principal functionality. The second prototype is already made from high density fibre board (HDF) and is developed from the paper prototype as the best approximation of the final subsystem possible with the existing knowledge. As the second prototype does not fulfil its functions in the required quality, it has to be optimized further.

The iterative stages in the test series show how the subsystem matures in iterations. These iterations are necessary as often only partial system behaviour can be evaluated based on the paper prototype (Hartmann et al., 2006; Klemmer et al., 2006). In these iterations, the subsystem matures through the increased understanding of the system and its EFRs. The procedure is continued until a fully functional subsystem exists (Figure 1, right). (Matthiesen et al., 2017a)

\subsection{Data acquisition}

For investigating the research question, the gain of knowledge about EFRs in experimental tests has to be measured. In non-experimental tests, no specific assumptions about influences of parameters are documented, as for example the whole concept is tested in a single test. In experimental approaches, identification of EFRs is possible, as design parameters from the embodiment need to be specified and varied to determine their relation to system behaviour and function.

The tests done in these iterative development stages are documented and stored in test cards according to standardized templates on the project management board trello.com. The documentation is built up according to the design hypotheses templates (Matthiesen et al., 2017a). The templates query for the test hypotheses, the selected test procedure and the test results. The students can add images and videos to the template to supplement the documentation.

The raw data consist of the students' entries into the templates. No additional data have been surveyed in the study. The documentation is exported to Microsoft Excel® for processing. The processed data are the basis for the statistical analysis using IBM ${ }^{\circledR}$ SPSS ${ }^{\circledR}$ Statistics Version 25.0.

\subsection{Data processing}

In the following, the data processing from the templates to the statistic investigation is described. The processing starts at the end of the project and is therefore retrospective. The templates are sifted through by the authors and exported to Excel ${ }^{\circledR}$. This whole process, also including further analysis using statistical evaluation, is shown in Figure 2. 


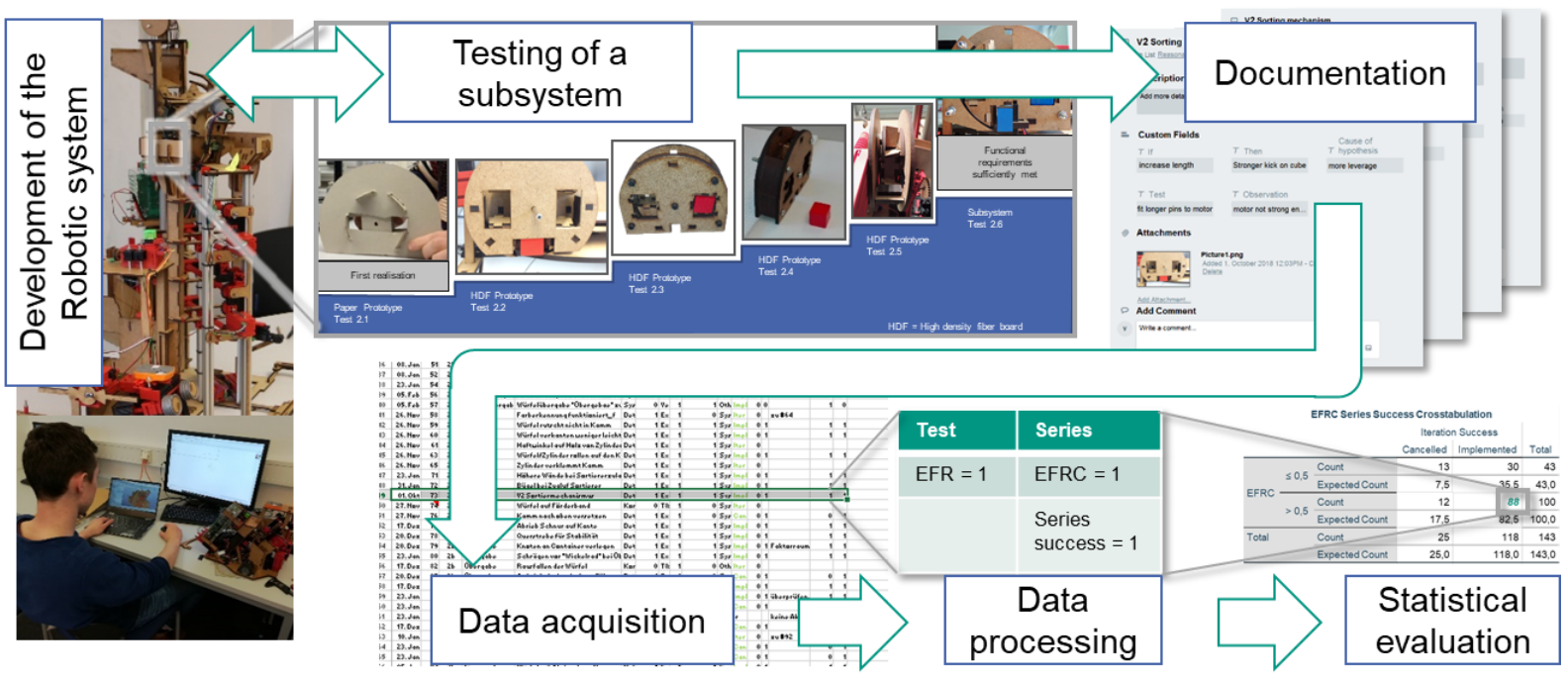

Figure 2: Testing and data acquisition using the example of a sorting mechanism of the stationary robotic system

This example of the sorting mechanism shows, how testing activities in the development of the robotic systems are documented. This documentation is acquired by the evaluators and the test cards are integrated into the Microsoft Excel ${ }^{\circledR}$ sheet as basis for processing and statistical evaluation using the Pearson-Chi²-Test. Figure 3 visualizes the observed and calculated variables and their interdependencies. The test series documentations are used as data points in this investigation and contain a value of the EFR Coefficient and Series success.

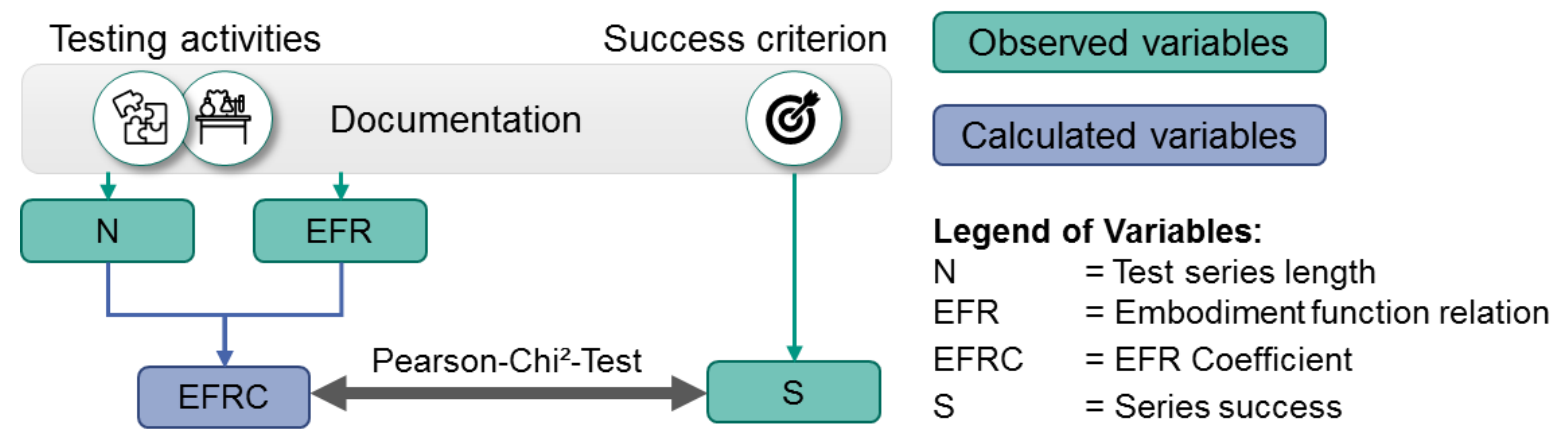

Figure 3: Relation between observed and calculated variables

In Figure 4, examples of test series with their individual tests and all recorded and processed data are shown. The right cluster shows the individual tests and their properties, read from the raw data as explained below Figure 4. The fourth test series shows the raw data of the test series displayed in Figure 1.

The left cluster gives an overview of obtained and calculated metadata of the test series: their length $N$ (derived from the latest test number), the calculated EFR Coefficient EFRC and the Series success $S$ of the test series. 


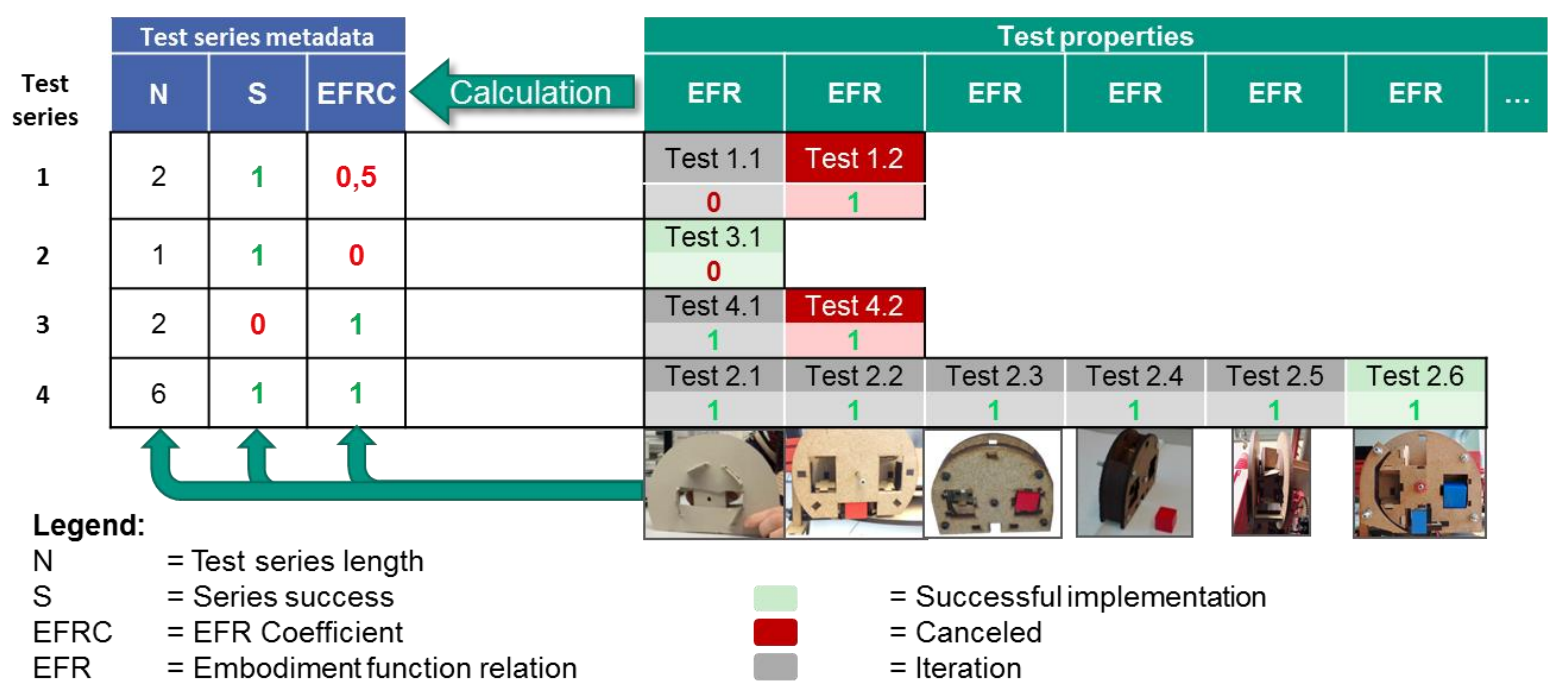

Figure 4: Visualization of data preparation and documentation

To gain the metadata for the test series and calculate the data point, it is first investigated whether an EFR could be identified in the test described in the template. The variable EFR needs two prerequisites to be checked, before a value can be assigned:

1. A design parameter is purposefully varied and is recognizable as an actuating variable of the test.

Besides quantitatively described parameters (e.g. length $=5 \mathrm{~mm}$ ) also qualitative parameters (e.g. length $2>$ length 1) are permissible.

2. A functional or behavioural parameter is recognizable as a target variable, which can be quantitative (e.g. speed $3 \mathrm{~m} / \mathrm{s}$ ) or qualitative (e.g. system 1 is faster than system 2 ).

If these prerequisites are met, the variable EFR is assigned the binary attribute "1". Otherwise the attribute " 0 " is allocated. The latter might be the case if the actuating variable describes a function or behaviour, or if an over-determined test is planned, in which several design parameters are changed without a corresponding test plan.

The variable Series success is a binary variable based on whether an identified test series in the development of a subsystem leads to its fulfilment of the success criterion (e.g. implementation into the subsystem).

For determining the test series $N$, test numbers are assigned to individual tests. These numbers are also used to measure the length of the test series. The test number count increases when a subsequent test is conducted within similar system boundaries. The test series ends when no subsequent test is identified. Each test is classified as a development stage in a test series. Individual tests are treated as separate test series with zero iterations, if no preceding or subsequent test is identifiable. For measuring the Series success, only the final result of the test series is evaluated.

The evaluation of test series considers different approaches of design engineers in building and extending their model of the EFRs. Some design engineers think long and hard about their system and can then reach their aim through a few well thought out tests, while others prefer fast testing and reach their aim in the same time with many iterations and a similar quality of the mental model.

As in a real design development, students must decide at the end of each test whether the developed subsystem will either be implemented in the system, further developed or discarded. The number of necessary iterations is not fixed and cannot be compared to an ideal value, as each development of a subsystem is done individually.

The variable EFR Coefficient $(E F R C)$ is needed to measure the gained insights about EFRs. This variable is calculated dividing the count of tests within a test series containing the attribute $E F R=1$ through the number of all tests within the series $(N)$. This indicates the share of EFRs examined per test series.

$$
E F R C=\frac{\sum E F R}{N} \epsilon[0 . .1] .
$$


For later statistical evaluation a Pearson-Chi²-Test is conducted that requires the considered variable to be categorized in two groups. Series success is already a binary variable and therefore only two values can be assigned. The calculated indicator variable for experimental tests $E F R C$ is not binary as with larger test series, values between 0 and 1 can occur. For the Pearson-Chi²-Test, it needs to be categorised in two groups as well. The categories are chosen as "high" and "low" EFRC. An EFRC $\leq 0.5$ is defined by the evaluators as low and a $E F R C>0.5$ is considered high.

The students' development procedure and the procedure for processing the recorded data are shown graphically in Figure 5. Here, on the left a typical development is shown, where a subsystem is built up and tested. The testing activities are documented in the trello board.

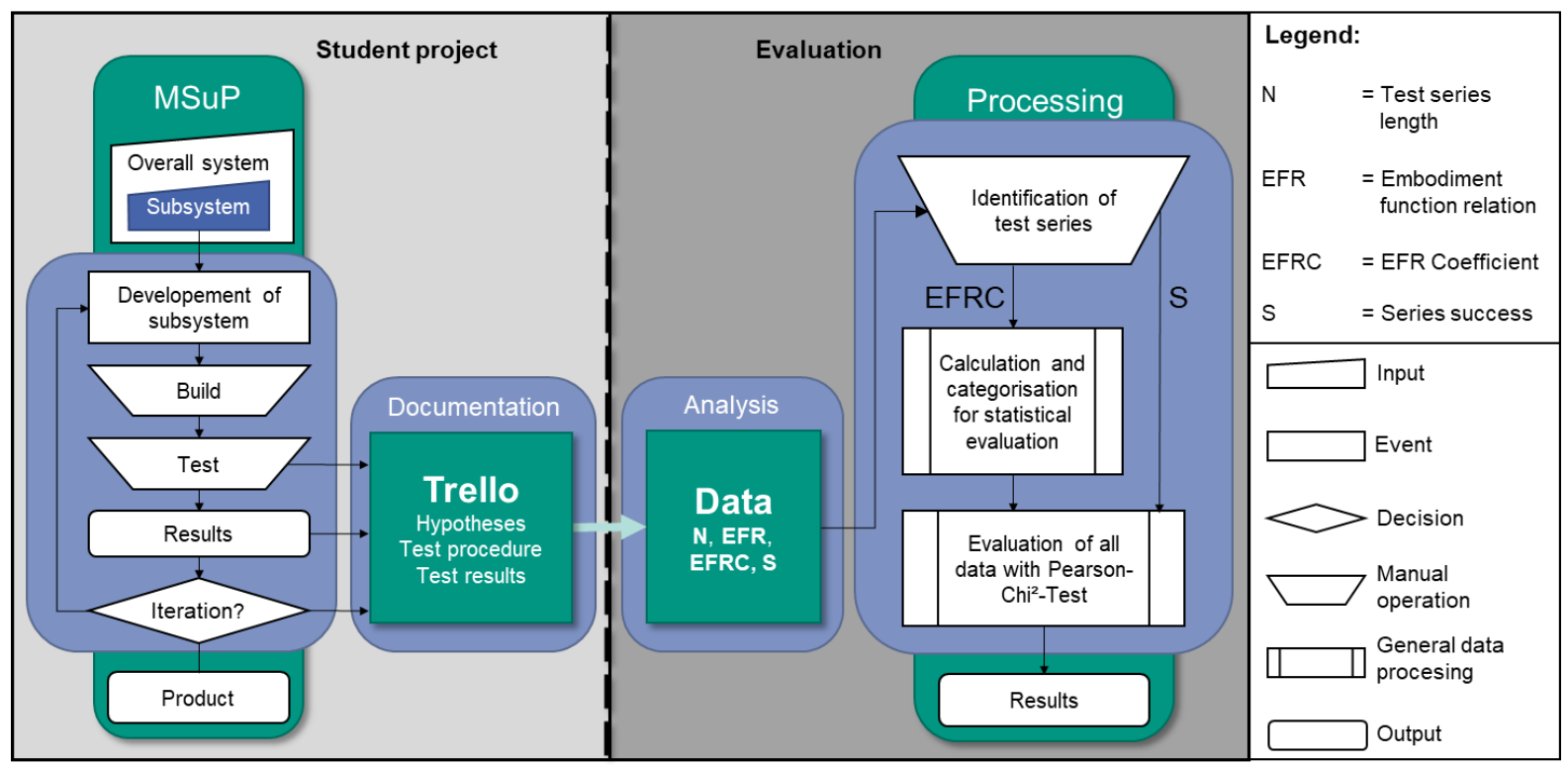

Figure 5: Development and data acquisition in the development projects in Mechatronic Systems and Processes (MSuP) (legend see also DIN 66 001)

\subsubsection{Statistical evaluation}

For statistical evaluation, at first the normal distribution of the $E F R C$ in its frequency of occurrence is tested using the Kolmogorov-Smirnov-Test. No independency of the recorded test series can be assumed, because the fact that the test planning, execution and documentation were often done by different students and no instructions are given regarding who had to plan or carry out the tests or how this should be done. A partly incomplete documentation situation is recognizable due to some missing intermediate results and different documentation rigor of the groups. Evaluation using the Pearson$\mathrm{Chi}^{2}$-Test is possible with the variables to derive statistical statements about the correlation and effect power.

\section{RESULTS}

In the following section, the quantitative properties of the data points and the model results are described.

\subsection{Occurrence frequency of variables}

The evaluation has been conducted based on 294 documented individual tests in total, of which 59 had to be discarded due to invalid raw data (incomplete test documentation, misuse of the template for other problems or incomprehensible entries). For the evaluation, 235 individual tests in 143 test series could be used.

The EFR tags were assigned to each test based on the criteria described in section 2.3. There were 155 tests from which insights about EFRs have been gained and 80 tests from which no insights were documented.

From the 143 test series, 118 were successful, as an implementation of the developed subsystem was described, while 25 were discarded as failed or not implemented for other reasons. There were 28 test series containing more than one test. 
The EFRC was then calculated for the test series based on the formula in section 2.3. As a result of the short test series, the EFRC showed accumulations at the values "1" (103 series) and "0" (34 series). 9 test series had an EFRC between 0 and 1.

\subsection{Model results}

Since 115/143 (80.4\%) test series consist of only one individual test, most data cluster at the extrema of the EFRC scale and no normal distribution of the EFRC in its frequency of occurrence could be found by using the Kolmogorov-Smirnov-Test. The Pearson-Chi'-Test was used to determine the effect of higher or lower EFRC on the results of test series.

The results of the Pearson-Chi²-Test are summarized in Table 1. The Pearson-Chi'2-Value of 6.929 has to be compared to a standard table (implemented in IBM® SPSS ${ }^{\circledR}$ ) of critical values to determine the significance of the test, which is shown next to the Pearson-Chi ${ }^{2}$-Value and amounts to 0.008 . This means that the null hypothesis which equals the negative answer of the research question can be rejected with a $99.2 \%$ chance. The most conservative calculation (in this case the Continuity Correction) rejects this null hypothesis with a $98.3 \%$ chance.

Table 1 Quality values and significance of the Pearson-Chi'-Test

\begin{tabular}{l|llll} 
Resulting values & Value & $\begin{array}{l}\text { Asymptotic Significance } \\
\text { (2-sided) }\end{array}$ & $\begin{array}{l}\text { Rejection of Null- } \\
\text { hypothesis }\end{array}$ & Effect size \\
\hline Pearson Chi'-Value & 6.929 & 0.008 & $99.2 \%$ & 0.220 \\
$\begin{array}{l}\text { Continuity Correction } \\
\text { (conservative calculation) }\end{array}$ & 5.723 & 0.017 & $98.3 \%$ & -
\end{tabular}

The effect size of $0.22(\mathrm{p}=0.008)$, indicates a small to medium effect of the EFRC on the Series success according to Cohen (2013, pp. 223-225). In summary, the results show that basic statistic evaluation of the documented raw data is possible by using the chosen evaluation. A statement about the research question is possible through this analysis by conducting the Pearson $\mathrm{Chi}^{2}$-test on the variables EFRC and Series success.

\section{DISCUSSION}

Based on the results of this study, conducting experimental tests to investigate EFRs shows a correlation with the success criterion of meeting user requirements by Müller and Turner (2007). This means that conducting experimental tests to investigate EFRs can support design engineers in becoming more successful in engineering design. With this result, the research question can be answered positively. However, a limitation of this statement is, that the causality of this result cannot be shown in a field study, in which no external influences can be excluded or controlled. Besides this result, additional findings have emerged as is intended by the chosen study design. These findings will be discussed in the following.

The raw data indicate that even an unsuccessful test outcome in individual tests might not influence the overall success of a test series. This supports the statement of iterations as learning cycles by Meboldt et al. (2012), where failures can support engineering design through gained knowledge. For this gain of knowledge, sometimes even specially developed test benches are built up, which will never be used in the product, but enable learning about the system (Ehrlenspiel and Meerkamm 2017, p. 630). This issue has not been investigated further but might be interesting to measure in following studies.

The student course MSuP provides a suitable amount of data for this investigation of testing activities, as many tests are necessary to reach the project aim and many iterations occur. The two systems to be developed have a considerable degree of complexity with many interacting subsystems. This approximates the development project complexity which design engineers in an industrial environment have to face. In this documentation, a bias is indicated towards complicated EFRs, as it can be assumed that many simple EFRs have been considered implicitly but were not documented. The bias towards complicated EFRs is unproblematic, as methodical support is not seen as necessary in simple tests (see Ehrlenspiel and Meerkamm, 2017, p. 84).

In this study, statements about gain of knowledge in physical tests can be made. However, some strategies to gain knowledge are not measurable with the set up data acquisition, which limits the range 
of the possible results and shows potential for further research. The presented data acquisition can only measure physical testing activities, which might induce a bias towards strategies relying on them. Strategies such as using expert evaluation for gain of knowledge can only be measured in their results, if the validation test is successful. However, no data about the process of learning about the systems EFRs can be gained by this study.

For investigating Series success, test series are identified using criteria of system boundary similarity. This enables retrospective connection of individual tests to test series. However, it bears the risk of not identifying a test as part of a test series. To gain more precise data about the test series, an explicit documentation of whether a test belongs to a test series is necessary.

In this study the test documentation from the teams was partly incomplete which might be due to misunderstandings of some students about what had to be documented. This incomplete documentation sometimes indicates preceding or succeeding tests that could not be analysed. This indicates that with higher documentation quality test series can be investigated in more detail. For future investigation, a clarification about the documentation of test results and especially test failures is important. In addition, methodical triangulation (compare Hussy et al. (2013)) using test observers might be an option.

The Series success is defined by whether or not the latest stage of the subsystem was implemented in the overall system, i.e. the effort put in this test series payed off. This categorisation assures low error possibilities in evaluation compared to more sophisticated success measurements such as how much the engineers learned or how well the function of the subsystem is fulfilled. However, cases occurred in which a technical solution was implemented without reaching the aimed function reliability. This was due to time constraints or insufficient risk assessment and is not sufficiently covered by the variable Series success. For future investigations, an experiment can help identify causes in which test series end before a certain level of function fulfilment is reached.

The EFR tag was set for the individual tests using the coding from section 2.3. As this approach is strongly influenced by the wording the teams use, it is possible that due to poor description, investigated EFRs are not identified or EFRs are described but the test does not gain insights about them. Errors made in assigning a test as containing an EFR have an influence on the calculated EFRC. In this study, the EFRC is sensitive to erroneous assignments of individual test $E F R s$, as many test series contain only one test. With improved documentation of iterations, this effect is reduced. Therefore in future studies it is important to get documentation of every stage of the subsystem that is tested.

\section{CONCLUSION AND OUTLOOK}

Literature indicates that gain of knowledge about embodiment function relations can offer support in embodiment design. To investigate this assumption, a field study in a student project course has been conducted. The students did a documentation of their testing activities, which was processed and investigated using the Pearson-Chi ${ }^{2}$-Test. The results show a positive correlation of a success criterion in design engineering and gaining insights about embodiment function relations. In addition, the field study shows findings about how knowledge is gained in testing activities. Based on this, a consecutive study will be conducted, with the focus on improvement of data acquisition. Data acquisition is already running in an identical environment with consideration of the discussed findings from this study. For investigation of causality of the still correlational result, an additional experimental study will be necessary. For this, the findings can be used to derive a suitable environment for the experiment.

\section{REFERENCES}

Albers, A. and Wintergerst, E. (2014), “The Contact and Channel Approach (C\&C²-A): relating a system’s physical structure to its functionality”, In: Chakrabarti, A. and Blessing, L.T.M. (Eds.), An Anthology of Theories and Models of Design: Philosophy, Approaches and Empirical Explorations, Springer, London, pp. 151-172.

Albers, A., Behrendt, M., Klingler, S., and Matros, K. (2016), "Verifikation und Validierung im Produktentstehungsprozess". In: Udo Lindemann (Hg.): Handbuch Produktentwicklung. Munich, Carl Hanser Verlag GmbH \& Co. KG, Germany, pp. 543-571.

Andreasen, M.M., Hansen, C.T. and Cash, P. (2015), Conceptual Design: Interpretations, Mindset and Models, Springer International Publishing, Cham, Switzerland.

Batliner, M., Boes, S., Heck, J., Meboldt, M. (2019), "Linking Testing Activities to Success in Agile Development of Physical Products", Research in Engineering Design, in review. 
Boes, S., Batliner, M., Stücheli, M. and Meboldt, M. (2017), A Taxonomy of Testing Activities in Product Development, ETH Zurich Research Collechtion, Zurich, Switzerland.

Camburn, B., Viswanathan, V., Linsey, J., Anderson, D., Jensen, D., Crawford, R., Otto, K. and Wood, K. (2017), "Design prototyping methods: state of the art in strategies, techniques, and guidelines" Des. Sci., vol. 3, e13, http://doi.org/10.1017/dsj.2017.10

Cohen, J. (2013), Statistical Power Analysis for the Behavioral Sciences, 2nd ed., Taylor and Francis, Hoboken. DIN 66 001:1983-12: "Informationsverarbeitung: Sinnbilder und ihre Anwendung"

Dorst, K. and Cross, N. (2001), "Creativity in the design process: co-evolution of problem-solution", Design Studies, Vol. 22 No. 5, pp. 425-437.

Ehrlenspiel, K. and Meerkamm, H. (2017), Integrierte Produktentwicklung: Denkabläufe, Methodeneinsatz, Zusammenarbeit, Vol. 6, vollständig überarbeitete und erweiterte Auflage, Carl Hanser Verlag GmbH \& Co. KG, Munich, Vienna.

Erbe, T. (2018), “CPM-Modeling in industry - a reflection”, In: Krause, D., Paetzold, K. and Wartzack, S. (Eds.), Design for X: Beiträge zum 29. DfX-Symposium, Tutzing, Germany.

Gero, J. S. and Kannengiesser, U. (2014), “The Function-Behaviour-Structure Ontology of Design”. In: Chakrabarti, A. and Blessing, L.T.M. (Eds.), An Anthology of Theories and Models of Design: Philosophy, Approaches and Empirical Explorations, Springer, London, pp. 263-283.

Hartmann, B., Klemmer, S.R., Bernstein, M., Abdulla, L., Burr, B., Robinson-Mosher, A. and Gee, J. (2006), "Reflective physical prototyping through integrated design, test, and analysis", In: Wellner, P. and Hinckley, K. (Eds.), Proceedings of the 19th annual ACM symposium on User interface software and technology - UIST '06, Montreux, Switzerland, 2006, ACM Press, New York, New York, USA.

Hussy, W., Schreier, M., Echterhoff, G. (2013): Forschungsmethoden in Psychologie und Sozialwissenschaften. Vol. 2, überarbeitete Auflage, Berlin, Heidelberg, Germany.

Klemmer, S.R., Hartmann, B. and Takayama, L. (2006), "How bodies matter”, In: Carroll, J.M., Bødker, S. and Coughlin, J. (Eds.), Proceedings of the 6th ACM conference on Designing Interactive systems - DIS '06, University Park, PA, USA, 26.06.2006 - 28.06.2006, ACM Press, New York, New York, USA, p. 140.

Matthiesen, S. (2002), "Ein Beitrag zur Basisdefinition des Elementmodells "Wirkflächenpaare \& Leitstützstrukturen” zum Zusammenhang von Funktion und Gestalt technischer Systeme”, Dissertation, Forschungsberichte des Instituts für Maschinenkonstruktionslehre und Kraftfahrzeugbau, University of Karlsruhe (TH), Karlsruhe, Germany.

Matthiesen, S. (2011), "Seven Years of Product Development in Industry - Experiences and Requirements for Supporting Engineering Design with 'Thinking Tools"', In: Proceedings of the 18th International Conference on Engineering Design. ICED’11. Copenhagen, Denmark. pp. 236-245.

Matthiesen, S., Grauberger, P., Nelius, T. and Hölz, K. (2017a), "Methodische Unterstützung des Erkenntnisgewinns in der Produktentwicklung durch Konstruktionshypothesen", KIT Scientific Working Papers, Vol. 61, Karlsruhe, Germany.

Matthiesen, S., Grauberger, P., Hölz, K., Nelius, T., Bremer, F., Wettstein, A., Gessinger, A., Pflegler, B., Nowoseltschenko, K., Voß, K. (2018), "Modellbildung mit dem C\&C²-Ansatz in der Gestaltung Techniken zur Analyse und Synthese”. KIT Scientific Working Papers, Vol. 58, Karlsruhe, Germany.

Meboldt, M., Matthiesen, S. and Lohmeyer, Q. (2012), "The Dilemma of Managing Iterations in Time-to-market Development Processes", In: 2nd International Workshop on Modelling and Management of Engineering Processes. MMEP, Cambridge, UK, pp. 127-139.

Müller, R. and Turner, R. (2007), "The Influence of Project Managers on Project Success Criteria and Project Success by Type of Project”, In: European Management Journal Vol. 25 No. 4, pp. 298-309.

Otto, K. and Wood, K. (2001), Product Design: techniques in reverse engineering and new Product Development, Prentice-Hall.

Shabi, J. and Reich, Y. (2012), "Developing an analytical model for planning systems verification, validation and testing processes", Advanced Engineering Informatics, Vol. 26 No. 2, pp. 429-438.

Tahera, K., Wynn, D.C., Earl, C. and Eckert, C.M. (2018), "Testing in the incremental design and development of complex products", Research in Engineering Design, Vol. 47 No. 2.

Türk, D., Leutenecker, B. and Meboldt, M. (2014), "Experience the relevance of testing in engineering design education", In: Proceedings of the 10th International CDIO Conference. Barcelona, Spain.

Weber, C. (2014), "Modelling Products and Product Development Based on Characteristics and Properties", In: Chakrabarti, A. and Blessing, L.T.M. (Eds.), An Anthology of Theories and Models of Design: Philosophy, Approaches and Empirical Explorations, Springer, London, pp. 327-352.

Wynn, D.C., Eckert, C. and Clarkson, P.J. (2007), “Modelling Iteration in Engineering Design”, In: International Conference on Engineering Design. ICED’07. Paris, France. 